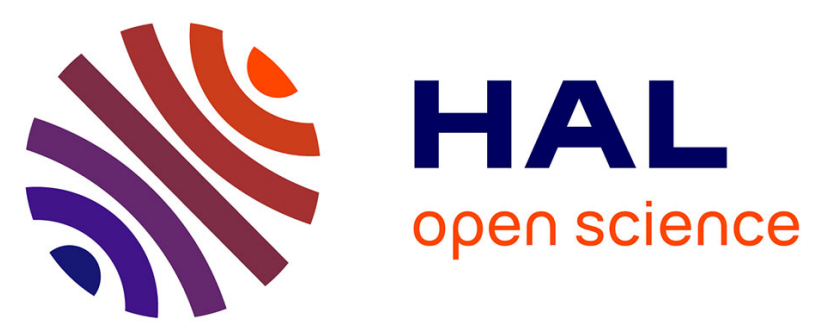

\title{
High performance low voltage organic field effect transistors on plastic substrate for amplifier circuits
}

Geoffroy Houin, Frederic Duez, Luc Garcia, Eugenio Cantatore, Fabrizio

Torricelli, Lionel Hirsch, Didier Belot, Claude Pellet, Mamatimin Abbas

\section{- To cite this version:}

Geoffroy Houin, Frederic Duez, Luc Garcia, Eugenio Cantatore, Fabrizio Torricelli, et al.. High performance low voltage organic field effect transistors on plastic substrate for amplifier circuits. Organic Field-Effect Transistors XV , Aug 2016, San Diego, CA, United States. pp.99430H, 10.1117/12.2238792 . hal-01534922

\section{HAL Id: hal-01534922 \\ https://hal.science/hal-01534922}

Submitted on 8 Jun 2017

HAL is a multi-disciplinary open access archive for the deposit and dissemination of scientific research documents, whether they are published or not. The documents may come from teaching and research institutions in France or abroad, or from public or private research centers.
L'archive ouverte pluridisciplinaire HAL, est destinée au dépôt et à la diffusion de documents scientifiques de niveau recherche, publiés ou non, émanant des établissements d'enseignement et de recherche français ou étrangers, des laboratoires publics ou privés. 


\title{
High performance low voltage organic field effect transistors on plastic substrate for amplifier circuits
}

\author{
G. Houin ${ }^{\mathrm{a}, \mathrm{b}}$, F. Duez ${ }^{\mathrm{b}}$, L. Garcia ${ }^{\mathrm{b}}$, E. Cantatore ${ }^{\mathrm{c}}$, F. Torricelli ${ }^{\mathrm{d}}$, L. Hirsch ${ }^{\mathrm{a}}$, D. Belot ${ }^{\mathrm{b}}$, C. Pellet ${ }^{\mathrm{a}}$, \\ M. Abbas ${ }^{\mathrm{a}}$ \\ ${ }^{a}$ CNRS, Université de Bordeaux, Laboratory IMS, UMR 5218, F-33607 Pessac, France ; \\ ${ }^{\mathrm{b} S T}$ Microelectronics, 850 rue Jean Monnet, 38920 Crolles, France ; \\ ${ }^{c}$ Eindhoven University of Technology, De Zaale, 5612 AJ Eindhoven, Nederland ; \\ ${ }^{\mathrm{d}}$ University of Brescia, Department of Information Engineering, via Branze 38, 25123 Brescia, Italia
}

\begin{abstract}
The high performance air stable organic semiconductor small molecule dinaphtho[2,3-b:2',3'-f]thieno[3,2-b]thiophene (DNTT) was chosen as active layer for field effect transistors built to realize flexible amplifier circuits. Initial device on rigid $\mathrm{Si} / \mathrm{SiO}_{2}$ substrate showed appreciable performance with hysteresis-free characteristics. A number of approaches were applied to simplify the process, improve device performance and decrease the operating voltage: they include an oxide interfacial layer to decrease contact resistance; a polymer passivation layer to optimize semiconductor/dielectric interface and an anodized high-k oxide as dielectric layer for low voltage operation. The devices fabricated on plastic substrate yielded excellent electrical characteristics, showing mobility of $1.6 \mathrm{~cm}^{2} / \mathrm{Vs}$, lack of hysteresis, operation below $5 \mathrm{~V}$ and on/off current ratio above $10^{5}$. An OFET model based on variable ranging hopping theory was used to extract the relevant parameters from the transfer and output characteristics, which enabled us to simulate our devices achieving reasonable agreement with the measurements
\end{abstract}

Keywords: organic field effect transistors, plastic substrate, parameter extraction, flexible amplifier

\section{INTRODUCTION}

Enormous research efforts over the last decade on organic semiconductors have led to impressive achievements in various devices which apply them as active materials. This has mainly been driven by coordinated developments in chemical and device engineering. Organic light emitting diodes (OLED) are already in the market. Organic photovoltaics (OPV) and organic field effect transistors (OFET) are starting to emerge as commercial products. It can be envisaged that low cost, flexible and large area devices made with these materials ${ }^{[1-3]}$ will soon enable new electronic applications.

Enabling the switching function, the field effect transistor (FET) is the single most important component in electronic circuits. OFETs have already shown better performances than that of the amorphous silicon, with the prospective to replace thin film transistors in active matrix displays. Several different types of circuits using OFETs have been proposed; among them were high gain inverters and $\mathrm{MHz}$ operation ring oscillators ${ }^{[4]}$. One of the major issues in the application of organic semiconductors is their operational stability, limiting their performance under ambient condition. A major breakthrough was achieved with the invention of dinaphtho[2,3-b:2',3'-f]thieno[3,2-b]thiophene (DNTT) ${ }^{[5,6]}$ (chemical structure is shown in Figure 1), which showed not only high performance, but also excellent air stability. Another issue is the operational voltage of OFETs. Oxygen plasma of Al gate together with self-assembled monolayer $(\mathrm{SAM})^{[7]}$ treatment of the surface yielded dielectric with very high capacitance, which allowed DNTT based OFETs operate at low voltage. However, simplification of the fabrication processes is necessary for large scale production of these devices.

In this paper, we report our approach to realize high performance, low voltage DNTT-based OFETs with special focus on process simplification. In this regard, we replaced oxygen plasma for the growth of $\mathrm{Al}_{2} \mathrm{O}_{3}$ with anodization, and SAM treatment with a polymer layer. We also applied oxide interfacial layer to reduce the contact resistance between the active layer and the electrode. These processes were carried out on plastic substrate, resulting in flexible OFETs operating below $5 \mathrm{~V}$, current on/off ratio above $10^{5}$ and mobility of $1.6 \mathrm{~cm}^{2} / \mathrm{Vs}$. The hysteresis-free characteristics of these devices allowed us to further exploit their applicability in amplifier circuits. We present device modeling for the 
extraction of relevant parameters. Simulated transfer and output characteristics obtained in the commercial CAD environment Virtuoso ${ }^{\circledR}$ were compared to experimental data obtaining good modeling accuracy. This allowed us to design an amplifier circuit using our OFET devices and passive components such as resistors and capacitors, a work which is still in progress.

\section{OFET DEVICE ENGINEERING}

\subsection{Silicon gate-based OFETs}

Our initial OFET, which served as the reference device, was fabricated on a Si substrate. Here below we describe the details of the fabrication process and the measured device performance.

\subsubsection{Fabrication process}

Highly n-doped silicon substrate with thermally grown $\mathrm{SiO}_{2}(200 \mathrm{~nm})$ was used as gate and dielectric in a bottom gate, top contact structure, as is shown in Figure 1. Surface treatment of the $\mathrm{SiO}_{2}$ was carried out using poly(1-vinyl-1,2,4-) triazole (PVT) (see Figure 1 for chemical structure) from a solution in water $(3 \mathrm{mg} / \mathrm{mL})^{[8]}$. PVT was deposited by spincoating and then dried in vacuum at $80^{\circ} \mathrm{C}$ for two hours forming about $15 \mathrm{~nm}$ of passivation layer. $30 \mathrm{~nm}$ of DNTT ptype semiconducting layer was evaporated thermally at slow rate $0.1 \AA /$ s under vacuum. We used gold as source/drain contact material. Gold was evaporated thermally through shadow mask to create a device with a channel length (L) of $100 \mu \mathrm{m}$ and a channel width (W) of $1 \mathrm{~mm}$.
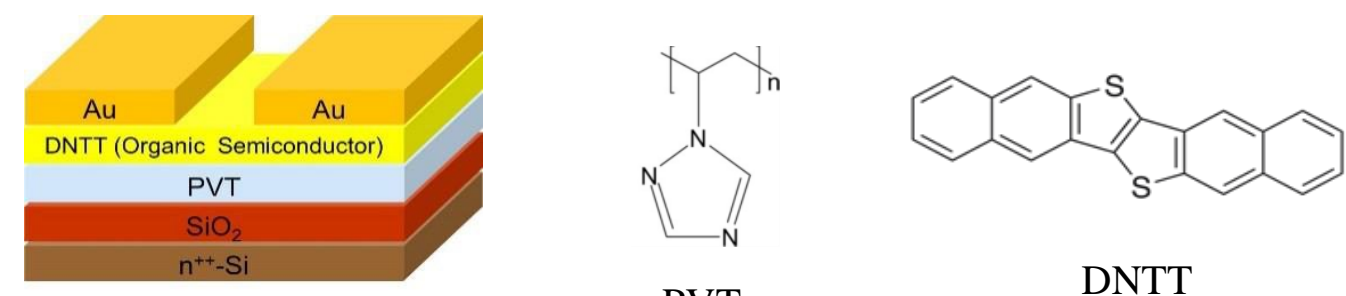

PVT

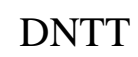

Figure 1. OFET architecture on Silicon substrate and molecular structure of PVT and DNTT.

\subsubsection{Results and discussions}

The electrical characteristics of a typical device are presented in Figure 2 a) and b). The transfer curve in saturation regime $\left(\mathrm{V}_{\mathrm{DS}}=-30 \mathrm{~V}\right)$ showed no hysteresis, thanks to the effective passivation of the oxide surface by PVT, which minimized interfacial trap densities. The steep subthreshold slope of around $0.2 \mathrm{~V} /$ decade, even with low total gate capacitance $\left(14.7 \mathrm{nF} / \mathrm{cm}^{2}\right)$, was also demonstrating the excellent dielectric/active layer interface. The on/off current ratio is higher than $10^{6}$ and a low threshold voltage of around $-3 \mathrm{~V}$ was obtained. The maximum saturation mobility $\mu_{\text {sat }}$ derived from gate voltage dependant mobility measurements is around $0.4 \mathrm{~cm}^{2} / \mathrm{Vs}$. Well defined linear and saturation behaviours are evident from the output curves. Despite of these excellent device performances, further improvements can be envisaged. The mobility of the device can be improved enhancing the charge injection from the source contact to the semiconductor layer, as well as by better charge transport at the interface between the dielectric and active layer. Operating voltages can be significantly decreased by applying high $\mathrm{k}$ dielectrics. With these strategies in mind, we developed low voltage, high performance OFET devices on plastic substrate, which will be described in the next section. 
a)

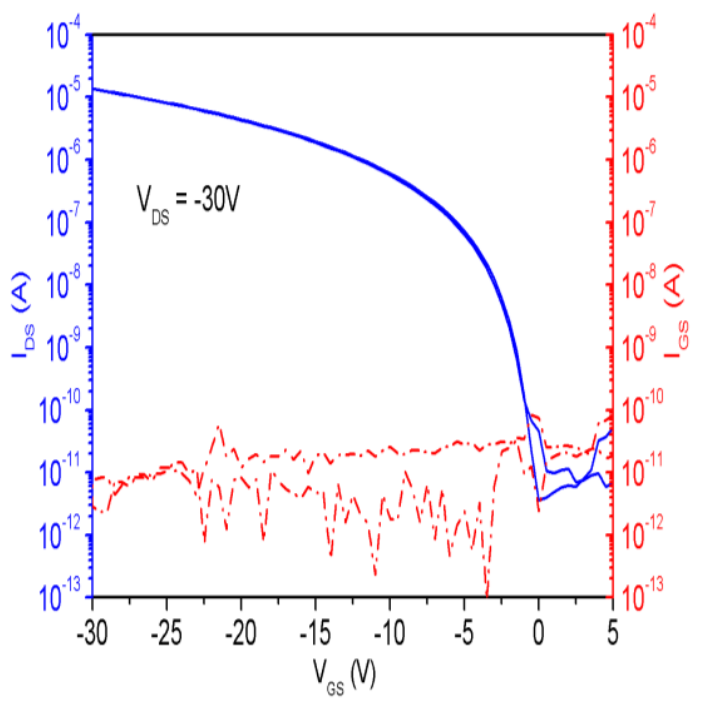

b)

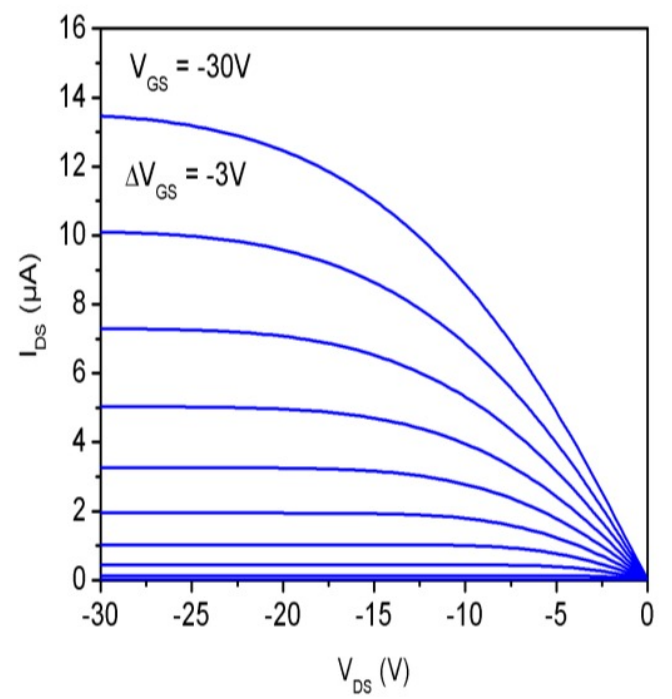

Figure 2. a)Transfer characteristics of reference OFET in saturation regime; b) corresponding output characteristics.

\subsection{OFETs on plastic substrates}

In each optimization step, the device on Si substrate served as reference. Firstly, an oxide interfacial layer was included in order to decrease the contact resistance between the charge injecting/extracting electrodes and the active semiconductor layer. Secondly, Polystyrene replaced PVT as the passivation layer on the gate insulator, due to its lower dielectric constant and the consequent reduction of interfacial dipoles which is detrimental to charge transport. Anodization of Al was chosen as simple step to grow high-k dielectric and obtain an high gate capacitance, which leads to low operating voltages. All processing was carried out on a plastic substrate, as will be described in detail below.

\subsubsection{Fabrication process}

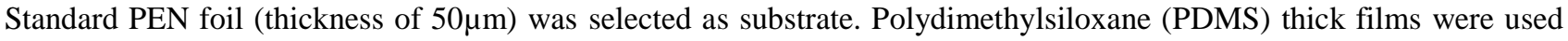
to facilitate the process (as support for evaporation and spin-coating). We applied surface annealing of PEN to smoothen its surface. $100 \mathrm{~nm}$ thick aluminum gate was evaporated under vacuum with an e-Beam evaporator. Aluminum oxide was formed by anodization using electrochemistry. A constant current was applied between the Al gate and platinum counter electrode in citric acid solution. Oxide thickness was controlled by increasing the voltage. The oxide layer thickness was estimated to be $30 \mathrm{~nm}$. Polystyrene in a solution of chlorobenzene $(3 \mathrm{mg} / \mathrm{mL})$ was chosen as surface treatment polymer to replace PVT, spin coated on the $\mathrm{Al}_{2} \mathrm{O}_{3}$ surface and dried in oven at $80{ }^{\circ} \mathrm{C}$ for two hours. $30 \mathrm{~nm}$ of DNTT was evaporated thermally at a slow rate under vacuum. $\mathrm{A} \mathrm{WO}_{3}(10 \mathrm{~nm}) / \mathrm{Au}$ combination for the contact material was thermally evaporated through a specifically designed shadow mask with $\mathrm{L}=50 \mu \mathrm{m}$ and $\mathrm{W}=500 \mu \mathrm{m}$. The final device structure is presented in Figure 3.

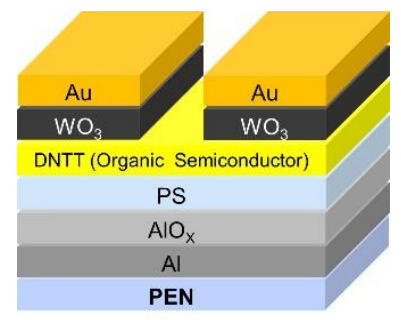

Figure 3. Optimized OFETs architecture on PEN substrate 


\subsubsection{Results and discussions}

The transfer and output characteristics of a typical device on plastic foil operating below $5 \mathrm{~V}$ are shown in Figure 4 a) and $b$ ). The maximum value of the gate voltage dependent mobility reached $1.6 \mathrm{~cm}^{2} / \mathrm{Vs}$. The on/off current ratio is higher than $10^{5}$. The devices did not show any hysteresis, which is a basic requirement for circuit design.

a)

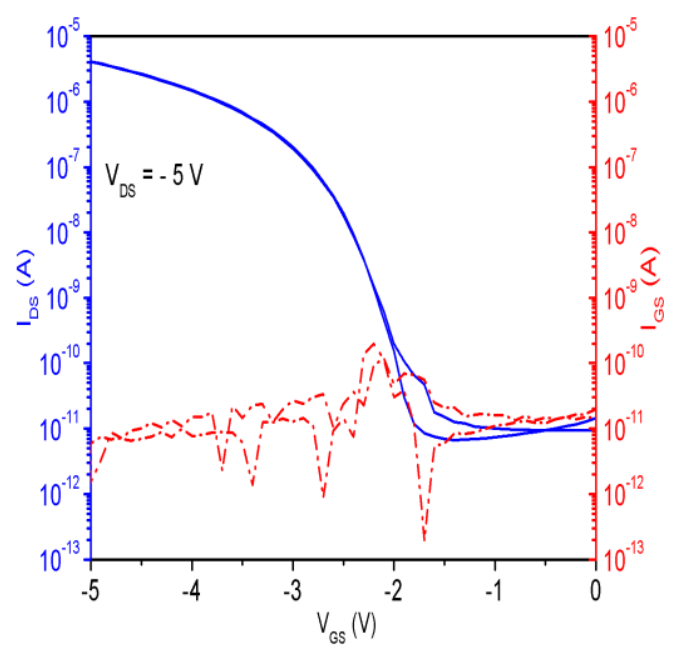

b)

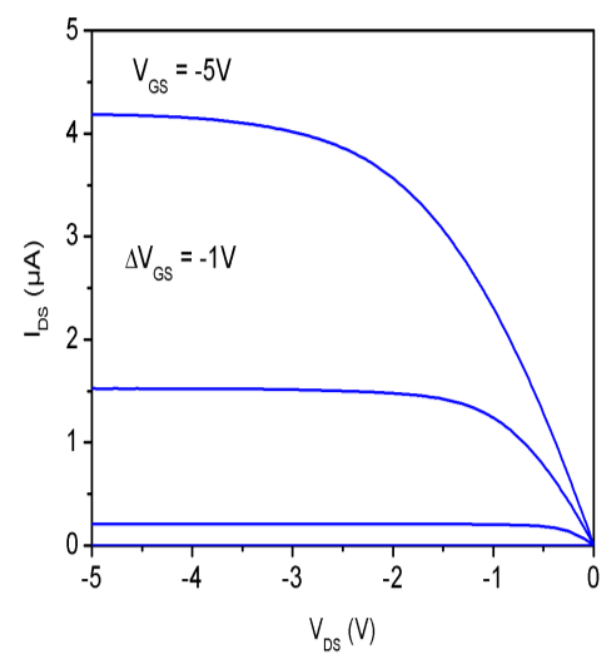

Figure 4. a) Transfer characteristics of optimized OFET in saturation regime on plastic substrate; b) corresponding output characteristics

The enhancement of device mobility from $0.4 \mathrm{~cm}^{2} / \mathrm{Vs}$ on $\mathrm{Si}$ substrate to $1.6 \mathrm{~cm}^{2} / \mathrm{Vs}$ on plastic substrates can be attributed mainly to two factors. One is the role of $\mathrm{WO}_{3}$ as the interfacial layer for efficient charge injection from the electrode to the active layer, which effectively reduces the contact resistance. Detailed discussions on the different oxide and metal combinations, energy level alignment and quantitative contact resistance analysis are going to be described in a separate publication. Another factor is the application of polystyrene (PS) as a passivation layer. Here the low dielectric constant of PS $(\varepsilon \sim 2-3)$ has weaker dipole at the interface comparing to PVT ( $\varepsilon \sim 5-6)$, which is beneficial for charge transport ${ }^{[9]}$. Such an excellent performance allowed us to take next step towards amplifier circuit design.

\section{MODELING}

\subsection{Transistor model}

Several models were developed for a p-channel OFET ${ }^{[10,11]}$. We based all our simulations on the model developed by D. Raiteri et al. ${ }^{[12]}$. It applies Variable Range Hopping ${ }^{[13]}$ theory for organic semiconductors. Note that this model is using a bottom and a top gate. It has been demonstrated that the drain-source current ( $\left.\mathrm{I}_{\mathrm{DS}}\right)$ in an organic semiconductor can be expressed as follows:

$$
\begin{gathered}
\mathrm{I}_{\mathrm{DS}}=\frac{W}{L} \beta\left[V_{O D, S}{ }^{\gamma}-V_{O D, D} \gamma\right]\left(1+\frac{V_{D S}}{E_{P} L}\right)+\frac{W}{L} \frac{V_{D S}}{R_{\text {sub }}^{\prime}} \\
V_{O D, X}=V_{S S} \ln \left[1+\exp \left(\frac{V_{G}-V_{X}-V_{F B}+\eta\left(V_{G}-V_{S}\right)}{V_{S S}}\right)\right]
\end{gathered}
$$

Where $\mathrm{W}$ is the channel width, $\mathrm{L}$ is the channel length, $\beta$ is the current prefactor depending on all the electrical parameters characterizing the transport, including the insulator capacitance per unit area between the semiconductor and 
the gate, and $\gamma$ is the traps coefficient depending on the working temperature of the transistor and the characteristic temperature related to the disorder of the system. $\mathrm{V}_{\mathrm{OD}, \mathrm{X}}$ is the overdrive voltage for the drain or the source, $\mathrm{E}_{\mathrm{P}}$ is the pinch-off field depending on the early voltage $V_{P}$. $R_{\text {sub }}^{\prime}$ is the bulk resistance directly linked to the off current, $V_{S S}$ is the sub-threshold slope, $\mathrm{V}_{\mathrm{FB}}$ is the flat-band voltage that accounts for the charge neutrality in the metal-insulator organicsemiconductor structure. Finally $\eta$ is the top-gate coupling to which we will give a value of 0 , because our TFTs do not have a top-gate.

\subsection{Parameter extraction}

Simulation of OFET is necessary to predict the behavior of the final circuit structure ${ }^{[14]}$. To achieve this, an extraction of the parameters corresponding to our OFET device is needed.

Equations (1) and (2) give us 7 parameters, collected in Table 1, to be extract from transfer and output characteristics of the OFET.

The easiest parameter to obtain is the early voltage $\mathrm{V}_{\mathrm{P}}$ that can be extrapolated from the output curve, taking the slope for a low bias of $\mathrm{V}_{\mathrm{GS}}$ around the highest $\mathrm{V}_{\mathrm{DS}}$. Then we normalized this value to the channel length and we obtained the equivalent pinch-off electric field $\mathrm{E}_{\mathrm{P}}$.

Two functions can be used to determine the other coefficients from the transfer curves:

$$
\begin{aligned}
& w=\frac{\int I_{D S} d V_{G S}}{I_{D S}} \\
& z=\frac{\int I_{D S}{ }^{2} d V_{G S}}{I_{D S}}
\end{aligned}
$$

In saturation regime, we can write that:

$$
\begin{gathered}
w_{s a t}=\frac{V_{G S}}{\gamma+1}+\frac{V_{T}}{\gamma+1} \\
z_{\text {sat }}=\frac{W}{L} \frac{\beta}{\gamma+1}\left(V_{G S}-V_{T}\right)^{\gamma+1}
\end{gathered}
$$

Approximating equation (5) with a straight line $\gamma=\mathrm{mV}_{\mathrm{GS}}+\mathrm{q}$, we can immediately derive:

$$
\begin{aligned}
& \gamma=\frac{1}{m}-1 \\
& V_{T}=-\frac{q}{m}
\end{aligned}
$$

In a similar way, we can derive $\beta$ from equation (6). The subthreshold voltage $V_{\text {ss }}$ can be extracted from the transfer curve in saturation regime evaluating the slope $\mathrm{m}$ ' in the subthreshold region as indicated in equation (9):

$$
V_{S S}=\frac{\gamma \log (e)}{m^{\prime}}
$$

Finally, equation (10) and (11) allow us to extract $\mathrm{V}_{\mathrm{FB}}$ and $\mathrm{R}_{\text {sub. }}$

$$
\begin{gathered}
V_{F B}=V_{T}+\eta\left(V_{T G}-V_{S}\right) \\
R^{\prime} s u b=\frac{L}{W} \frac{V_{D S}}{I_{\text {off }}}
\end{gathered}
$$


Equation (10) in our case can be rewritten as $\mathrm{V}_{\mathrm{FB}}=\mathrm{V}_{\mathrm{T}}$, because we don't have top gate. All seven extracted parameters are compiled in Table 1, which will be used for simulation in the following section.

Table 1. Model parameters extracted from our device characteristics

\begin{tabular}{|c|c|c|c|c|}
\hline & Symbol & Extracted Value & Tuned Value & Unit \\
\hline Current prefactor & $\beta$ & $3 \times 10^{-6}$ & $1.1 \times 10^{-7}$ & {$\left[\mathrm{~A} / \mathrm{V}^{\gamma}\right]$} \\
\hline Traps coefficient & $\gamma$ & 2 & 2.2 & {$[\mathrm{~K} / \mathrm{K}]$} \\
\hline Sub-threshold slope & $\mathrm{V}_{\mathrm{SS}}$ & 0.03 & 0.18 & {$[\mathrm{~V}]$} \\
\hline Flat-band voltage & $\mathrm{V}_{\mathrm{FB}}$ & -2.3 & -2.3 & {$[\mathrm{~V}]$} \\
\hline Bulk resistance & $\mathrm{R}_{\text {sub }}$ & $6 \times 10^{10}$ & $6 \times 10^{11}$ & {$[\Omega]$} \\
\hline Pinch-off field & $\mathrm{E}_{\mathrm{P}}$ & $1 \times 10^{5}$ & $1 \times 10^{5}$ & {$[\mathrm{~V} / \mathrm{cm}]$} \\
\hline Top-gate coupling & $\eta$ & $/$ & $/$ & {$[\mu \mathrm{m} / \mu \mathrm{m}]$} \\
\hline
\end{tabular}

\section{SIMULATION}

We use CADENCE Virtuoso ${ }^{\circledR}$ to run a simulation of our OFET characteristics. Then we compared them to our devices measurements.

Using a classical scheme to test our device in simulation ( $\mathrm{I}_{\mathrm{DS}}$ as function of $\mathrm{V}_{\mathrm{GS}}$, Figure 5 a) and $\mathrm{I}_{\mathrm{DS}}$ as function of $\mathrm{V}_{\mathrm{DS}}$ figure 6 a)), we observed that the model fitted well with the parameters that we extracted. However, the fitting could be further improved. We studied the influence of each parameter on transfer and output curves to find the optimal values for all seven parameters.

Figure 7 shows the way to proceed to tune the parameters to fit the best model with the experimental data.

Table 1 gathered all the new optimized values for the model parameters.

a)

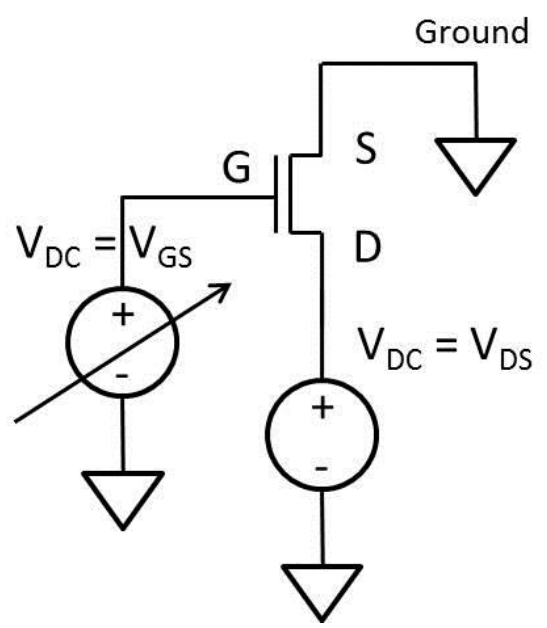

b)

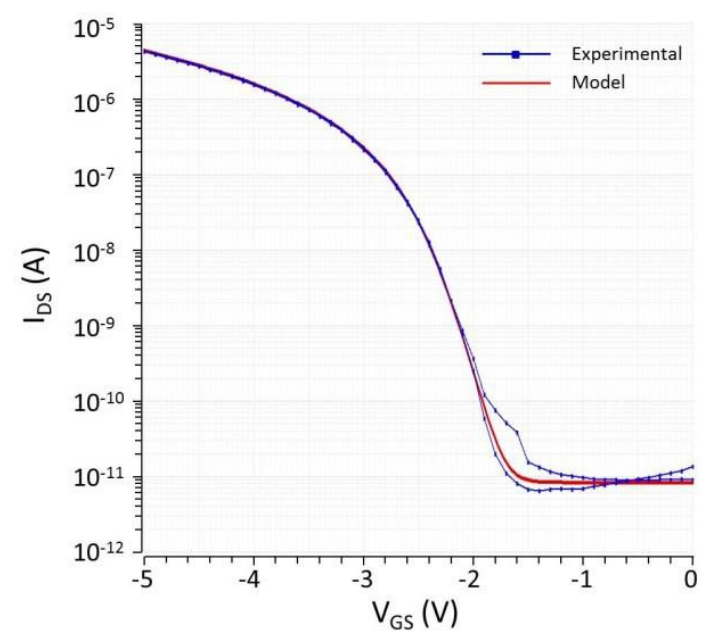

Figure 5. a) device operation scheme; b) Fitting of the model to the experimental transfer curve using optimally tuned values 
a)

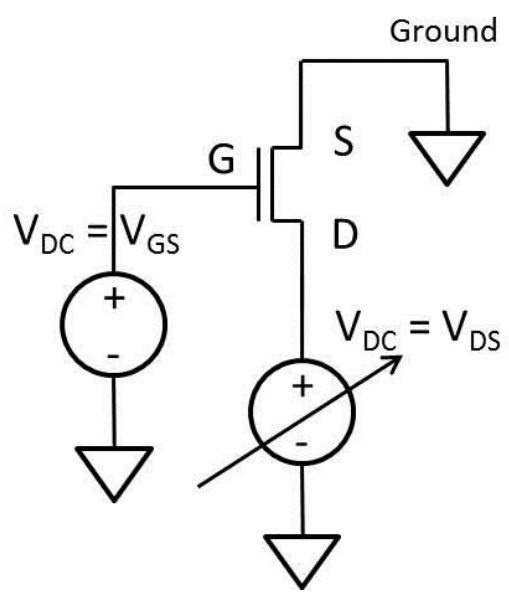

b)

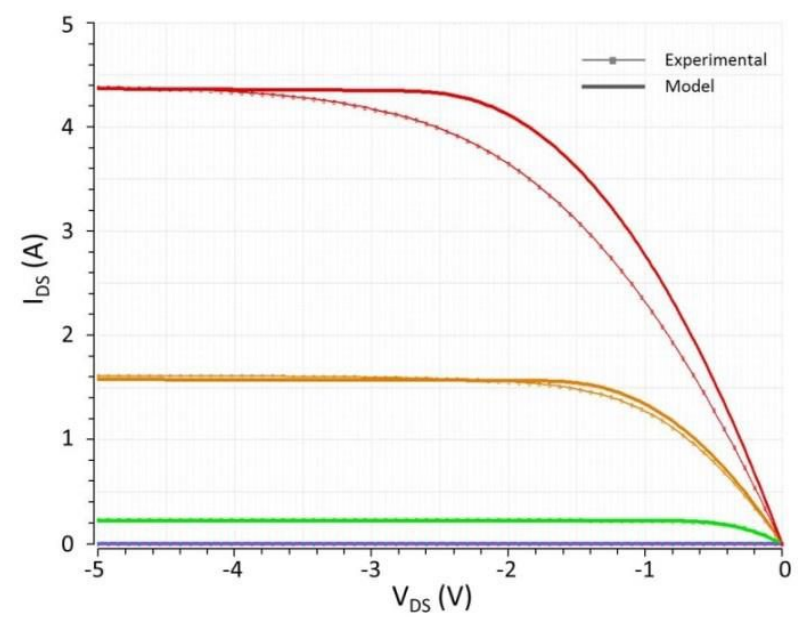

Figure 6. a) device operation scheme; b) Fitting of the model to the experiment output curves using optimally tuned values

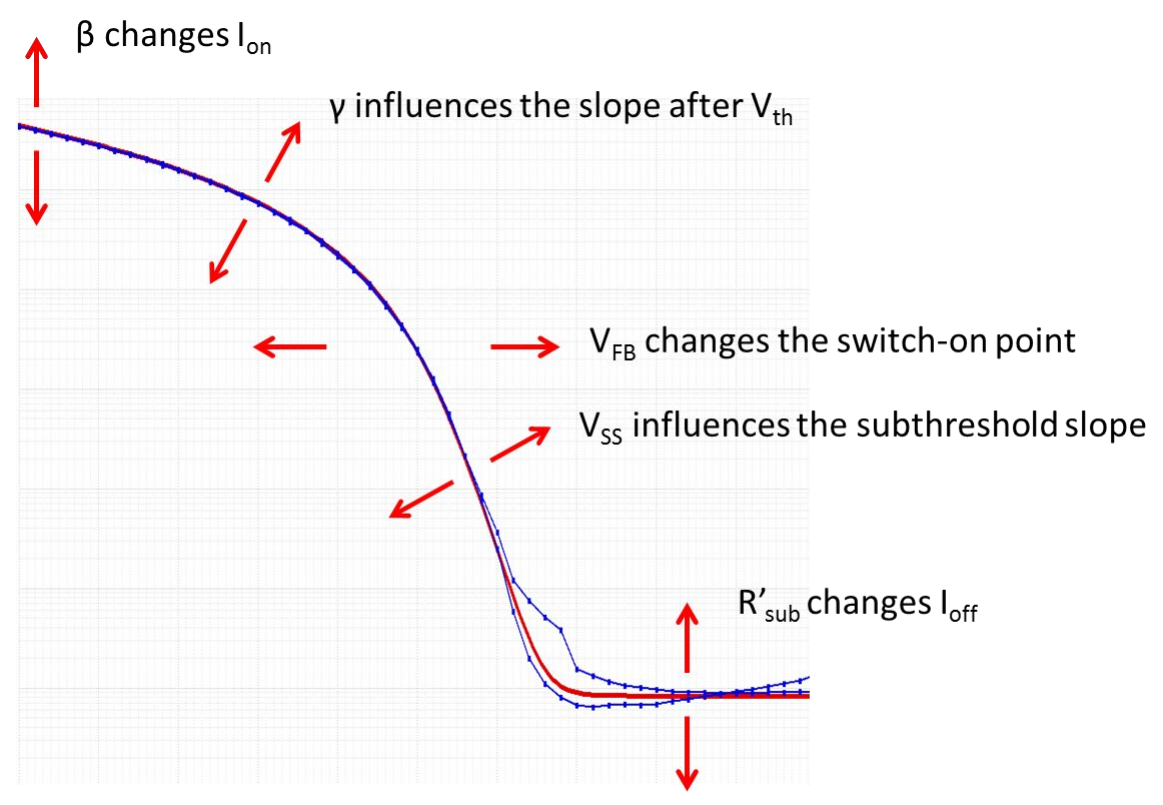

Figure 7. Optimization possibilities to get the best fitting between experimental and simulations

We focus on the transfer curve to tune the parameter values, but we also observed some influences on the output curves: $E_{P}$ has a mild influence on the slope in saturation (remind that our OFETs are long); $\beta$ changes the separation of the curves for different gate voltages, $\gamma$ increases or decreases the maximum drain current; $V_{S S}$ helps to increase the maximum current; $\mathrm{R}^{\prime}$ sub has no relevant influence. At last, when $\mathrm{V}_{\mathrm{FB}}$ decreases, $\mathrm{I}_{\mathrm{DS}}$ also decreases.

This allowed us to design an amplifier circuit composed of our OFETs and passive components such as resistor and capacitor. Work is in progress towards manufacturing such an amplifier on plastic substrate. 


\section{CONCLUSION AND PERSPECTIVES}

In this work, we presented our approach to fabricate high performance OFET devices on plastic substrate, which are used to realize a flexible amplifier. Air-stable organic semiconductor small molecule DNTT acted as active layer. We first fabricated our device on rigid $\mathrm{Si} / \mathrm{SiO}_{2}$ substrate as control device, then used a number of approaches to improve device performance on a plastic substrate. Our focus has been on simplifying fabrication process. Solution processing anodization was used to grow high $\mathrm{k}$ dielectric $\mathrm{Al}_{2} \mathrm{O}_{3}$ with controllable thickness. Simple spin coating of a polymer was applied to passivate the oxide surface. With low dielectric constant, polystyrene proved to yield the best performance. We also observed that application of an oxide interfacial layer $\left(\mathrm{WO}_{3}\right)$ decrease the contact resistance between the electrode and the semiconductor layer. All these attempts resulted in a device fabricated on plastic substrate with excellent electrical characteristics showing mobility of $1.6 \mathrm{~cm}^{2} / \mathrm{Vs}$, lack of hysteresis, and current on/off ratio above $10^{5}$, while operating below 5V. An OFET model was used to extract the relevant parameters from transfer and output characteristics of our device, which enabled us to simulate the OFET and compare the results with experimental measurements, achieving good agreement. Based on these parameters, an amplifier circuit was designed consisting of our p-type OFET and passive components such as resistances and capacitors. Work is in progress to optimize these passive components and include them in the amplifier together with our newly developed OFET.

\section{REFERENCES}

[1] Myny, K., Steudel, S., Smout, S., Vicca, P., Furthner, F., Van der Putten, B., Tripathi, A.K., Gelinck, G.H., Genoe, J., Dehaene, W. and Heremans, P., "Organic RFID transponder chip with data rate compatible with electronic product coding," Org. Electron. 11, 1176-1179 (2010).

[2] Usta, H., Facchetti, A. and Marks, T. J., "n-Channel semiconductor materials design for organic complementary circuits," Acc. Chem. Res. 44, 501-510 (2011).

[3] Liu, X. M., Long, Y. Z., Liao, L., Duan, X. and Fan, Z., "Large-Scale Integration of Semiconductor Nanowires for High-Performance Flexible Electronics," ACS Nano 6, 1888-1900 (2012).

[4] Zschieschang, U., Hofmockel, R., Rödel R., Kraft, U., Kang, M. J., Takimiya, K., Zaki, T., Letzkus, F., Butschke J., Richter H., Burghartz J. N. and Klauk, H., "Megahertz operation of flexible low-voltage organic thin-film transistors," Org. Electron. 14, 1516-1520 (2013).

[5] Yamamoto, T. and Takimiya, K., "Facile Synthesis of Highly $\pi$-Extended Heteroarenes, Dinaphtho[2,3-b:2',3'f]chalcogenopheno[3,2-b]chalcogenophenes, and Their Application to Field-Effect Transistors," J. Am. Chem. Soc. 129, 2224-2225 (2007).

[6] Yamamoto, T. and Takimiya, K., "FET Characteristics of Dinaphthothienothiophene (DNTT) on Si/SiO2 Substrates with Various Surface-Modifications," J. Photopolym. Sci. Technol. 20, 57-59 (2007).

[7] Zschieschang, U., Kang, M.J., Takimiya, K., Sekitani, T., Someya, T., Canzler, T.W., Werner, A., BlochwitzNimoth, J. and Klauk, H., "Flexible low-voltage organic thin-film transistors and circuits based on C10- DNTT," J. Mater. Chem. 22, 4273-4277 (2012).

[8] Thuau, D., Abbas, M., Chambon, S., Tardy, P., Wantz, G., Hirsch, L., Dufour, I., Poulin, P. and Ayela, C., "Sensitivity enhancement of polymeric MEMS strain sensor with combination of an organic field effect transistor," Org. Electron. 15, 3096-3100 (2014).

[9] Veres, J., Ogier, S. and Lloyd, G., "Gate insulators in organic field effect transistors," Chem. Mater. 16, 4543-4555 (2004).

[10] Iniguez, B., Pallarès, J., Marsal, L. F., Castro-Carranza, A., Cerdeira and A., Estrada, M., "Compact modeling of organic thin-film transistors," IEEE 978-1-4244-5798-4, 1268-1271 (2010).

[11] Yaglioglu, B., Agostinelli, T., Cain, P., Mijalkovic, S. and Nejim, A., "Parameter extraction and evaluation of UOTFT, Model for organic thin-film transistor, Circuit design," J. of display technology, 9(11), 890-894 (2013).

[12] Raiteri, D., Cantatore, E., and Van Roermund, A.H.M., "Circuit Design on Plastic Foils," Springer, Cham, ISBN 978-3-319-11426-2, 24-39 (2015).

[13] Vissenberg, M., and Matters, M., "Theory of the field-effect mobility in amorphous organic transistors," Physical Review B., 57(20), 964-967 (1998). 
[14] Abdinia, S., Torricelli, F., Maiellaro, G., Coppard, R., Daami, A., Jacob, S., Mariucci, L., Palmisano, G., Ragonese, E., Tramontana, F., Van Roermund, A.H.M. and Cantatore, E., "Variation-based design of an AM demodulator in a printed complementary organic technology," Organic Electronics, 15, 4, 904-912 (2014).

Proc. of SPIE Vol. $994399430 \mathrm{H}-9$ 